\title{
Changing of the Spontaneous Polarization in Niobate Nanoparticles Induced by Non Isovalent Doping
}

\author{
Caio Vinicius de Lima ${ }^{a}$, Marcos Augusto Lima Nobre ${ }^{b}$ \\ Silvania Lanfredic
}

\begin{abstract}
Laboratório de Compósitos e Cerâmicas Funcionais- LaCCeF, Fac de Ciências e Tecnologia FCT, Univ Estadual Paulista - UNESP, P.O Box 467, CEP 19060-900, Presidente Prudente-SP, Brazil.

acaiovlima@hotmail.com, ${ }^{\mathrm{b}}$ nobremal@fct.unesp.br, 'silvania@fct.unesp.br
\end{abstract}

Keywords: Niobate, Tetragonal Tungsten Bronze Structure, Spontaneous Polarization.

\begin{abstract}
Ferroelectric niobates with tetragonal tungsten bronze TTB-type structure have shown great technology interest for application in pyroelectric detectors and piezoelectric transducers, sensor/filter in composite. The synthesis and structural characterization of the solid solution of iron doped potassium strontium niobate with stoichiometry $\mathrm{KSr}_{2}\left(\mathrm{Fe}_{0.25} \mathrm{Nb}_{4.75}\right) \mathrm{O}_{15-\delta}$ prepared by modified polyol method were carried out. The highest crystallinity was obtained for the precursor powder calcined at $1150^{\circ} \mathrm{C}$ for 10 hours in oxygen atmosphere. The structural characterization was performed by X-Ray diffraction. The average crystallite size obtained was equal to $25 \mathrm{~nm}$. The structural parameters were determined by Rietveld method giving a tetragonal system with space group $\mathrm{P} 4 \mathrm{bm}$. The spontaneous polarization of the solid solution was calculated, being equal to $39.46 \mu \mathrm{C} . \mathrm{cm}^{-2}$. Polihedra distortion and its correlation with niobium off-center are discussed.
\end{abstract}

\section{Introduction}

Materials with a tetragonal tungsten bronze (TTB)-type structure, similar to those of perovskites, have shown high dielectric constants, large spontaneous polarization, ferroelectric and piezoelectric properties [1]. The TTB-type structure can be considered a derivative of the classical perovskite structure. It can be described by the chemical formula $\left[\left(\mathrm{A}_{1}\right)_{2}\left(\mathrm{~A}_{2}\right)_{4}(\mathrm{C})_{4}\right]\left[\left(\mathrm{B}_{1}\right)_{2}\left(\mathrm{~B}_{2}\right)_{8}\right] \mathrm{O}_{30}$, where $\mathrm{A}$ sites is normally occupied by divalent and trivalent cations and the $\mathrm{B}$ sites by pentavalent atoms. Small cations like $\mathrm{Li}$ are found in the $C$ site [2]. Three different types of structural cavities, i.e., pentagonal, square, and trigonal tunnels, are available for cation inclusion. Typically, the cavity size decreases in the order $A_{2}>A_{1}>C[3,4]$ and $B_{1} \sim B_{2}$. As an example, Fig. 1 shows the TTB structure of $\mathrm{Sr}_{2} \mathrm{KNb}_{5} \mathrm{O}_{15}$. In Fig. 1, the trigonal site is vacant. In $\mathrm{Sr}_{2} \mathrm{KNb}_{5} \mathrm{O}_{15}$ structure, $\mathrm{Nb}^{5+}$ cations can be differentiated as $\mathrm{Nb}(1)$ and $\mathrm{Nb}(2)$, because they occupy two non-equivalent octahedral [5]. Both types of niobium atoms form their own chains based on the vertex-shared octahedra $\left[\mathrm{NbO}_{6}\right]$. O-ring of five octahedra gives origin to a pentagonal site $\mathrm{A}_{2}$ occupied by potassium and strontium cátions. On the other hand, two $\mathrm{Nb}(2)$ octahedra accompanied of others two $\mathrm{Nb}(2)$ niobium octahedra belonging to another ring forming a square-ring containing four $\mathrm{Nb}(2)$ octahedra that give origin to the tetragonal site $A_{1}$ being all octahedral exhibit very low or absent average rotation degree. Since oxygens belong to (ab)-plane and some niobium octraedron, as well as alkaline and alkaline earth polyhedron sharing a corner, distortions of niobium octahedron take place with changing of the off-center position which is accommodate by changing of bond length of basal plane of octahedron. The $\mathrm{Nb}(2)$ that coordinates the pentagonal site occupied by alkaline cation $(\mathrm{K})$ and alkaline earth cation (Sr) exhibits a minor niobium off-center magnitude showing some kind of compromise between shifting of niobium along c-axis and octahedron rotating along c-axis. 


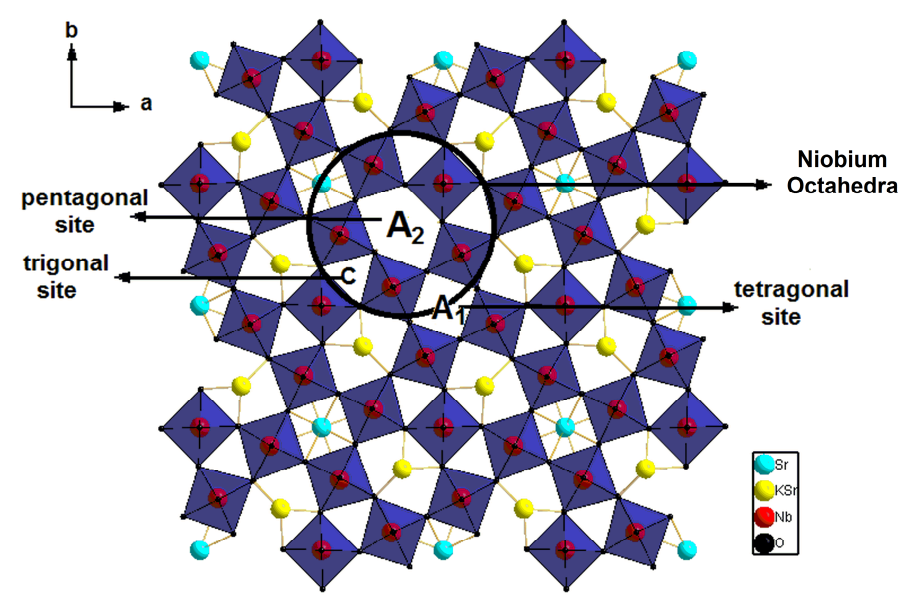

Fig. 1. Representation of the tetragonal tungsten bronze (TTB)-type structure of $\mathrm{Sr}_{2} \mathrm{KNb}_{5} \mathrm{O}_{15}$, where $\mathrm{A}_{1}, \mathrm{~A}_{2}$, and $\mathrm{C}$ represent the tetragonal, pentagonal and trigonal sites, respectively [5].

Considering the TTB structure, a wide variety of cation substitutions is possible. Thus, the composition and the distribution of metal ions in different interstices of TTB-type structure has a strong influence on the physical properties of these materials, such as electro-optic, ferroelectric, pyroelectric and electrical properties. In the ferroelectric region, TTB niobates have high spontaneous polarization at room temperature $(20-40) \mu \mathrm{C} / \mathrm{cm}^{2}$ along the c axis. In addition, other factors can influence their electrical properties, such as processing, stoichiometry, chemical homogeneity, texture and densification. Some polycations oxides of TTB family have found applications in microwave telecommunications, satellites and other devices, particularly in the area of "wireless telecommunication". However, most of these materials is lead-based. Materials containing lead are used by the electronics industry in actuators, transducers and other electromechanical components, due to their ferroelectric and piezoelectric properties. However, the toxicity of lead has led to increased demand for alternative materials more environmentally friendly. In this work was studied the crystallographic characterization of a solid solution of iron-doped $\mathrm{KSr}_{2} \mathrm{Nb}_{5} \mathrm{O}_{15}$ with stoichiometry $\mathrm{KSr}_{2}\left(\mathrm{Fe}_{0.25} \mathrm{Nb}_{4.75}\right) \mathrm{O}_{15-\delta}$, prepared by Modified Polyol Method. Further, was investigated the influence of $\mathrm{Fe}^{3+}$ ions on the structural characteristics of the $\mathrm{KSr}_{2} \mathrm{Nb}_{5} \mathrm{O}_{15}$ host structure. The characterization and determination of the structural parameters were performed by X-ray diffraction and the structure refinement by the Rietveld method. Structural features are correlated to the spontaneous ferroelectric polarization.

\section{Materials and Methods}

Synthesis: $\mathrm{KSr}_{2}\left(\mathrm{Fe}_{0.25} \mathrm{Nb}_{4.75}\right) \mathrm{O}_{15-\delta}$ single-phase powder was synthesized by a Modified Polyol Method [6]. This method consists of reducing metal ions such as $\mathrm{Co}$ (II), $\mathrm{Fe}$ (III) and $\mathrm{Ni}$ (II) in alcoholic medium. The polyol typically used is the ethylene glycol, which operates in the reactional medium of simultaneous form such as solvent, reducing agent, passivating and reactional medium for the growth of the particles [6]. Starting reagents for the powder synthesis via chemical route were nitric acid, $\mathrm{HNO}_{3}$ (99.5\% Reagen), strontioum carbonate, $\mathrm{SrCO}_{3}$ (99.0\% Reagen), potassium carbonate, $\mathrm{K}_{2} \mathrm{CO}_{3}\left(99.0 \%\right.$ Reagen), iron oxide, $\mathrm{Fe}_{2} \mathrm{O}_{3}(99.0 \%$ Reagen), ethylene glycol, $\mathrm{HOCH}_{2} \mathrm{CH}_{2} \mathrm{OH}\left(98,0 \%\right.$ Synth) and niobium oxide, $\mathrm{Nb}_{2} \mathrm{O}_{5} .3 .28 \mathrm{H}_{2} \mathrm{O}$ (CBMM-Brazil). The reagents were dissolved in nitric acid and then $100 \mathrm{ml}$ of ethylene glycol was added. The solution was heated at $90^{\circ} \mathrm{C}$, promoting the decomposition of $\mathrm{NO}_{3}$ group [2,7]. After the polyesterification reaction, a polymeric gel is obtained. The polymer maintained in the beaker was subjected to a primary calcination in a box-type furnace. The heating cycle was carried out via a two-step calcination starting from room temperature. In the first step, the temperature was increased with a heating rate of $10^{\circ} \mathrm{C} / \mathrm{min}$ up to $150^{\circ} \mathrm{C}$. After total elimination of nitrous gases, the system still remained in 
heating to the formation of a polymeric resin that was pre-calcined at $150{ }^{\circ} \mathrm{C}$ for 1 hour and $300^{\circ}$ $\mathrm{C}$ for 2 hours in a nitrogen atmosphere. The Powder was deagglomerated in agate mortar with a 350-mesh minimum. Single phase powders were obtained after calcination at $1150^{\circ} \mathrm{C}$ for $12 \mathrm{~h}$. The precursor was calcined in a tube furnace under an integral oxygen atmosphere. An oxygen flow of $300 \mathrm{~mL} / \mathrm{min}$ was maintained during a complete thermal cycle. Structural characterization of the $\mathrm{KSr}_{2}\left(\mathrm{Fe}_{0.25} \mathrm{Nb}_{4.75}\right) \mathrm{O}_{15-\delta}$ powder was carried out by X-ray diffraction (XRD). A Siemens (model D5000) diffractometer with $\mathrm{Cu}-\mathrm{K} \alpha$ radiation $(\lambda=1.54 \AA)$ and a graphite monochromator were used. Measurements were carried out over an angular range of $5^{\circ} \leq 2 \theta \leq 80^{\circ}$ with a scanning step of $0.02^{\circ}$ and a fixed counting time of $10 \mathrm{~s}$. Divergence, scattered and receiving radiation slits were $1^{\circ}, 1^{\circ}$ and $0.2 \mathrm{~mm}$ respectively. The $\mathrm{KSr}_{2}\left(\mathrm{Fe}_{0.25} \mathrm{Nb}_{4.75}\right) \mathrm{O}_{15-\delta}$ structure was refined according to the Rietveld method using the Fullprof program [8]. The parameters and variables adopted during the refinement process were the background coefficients, profile coefficients, histogram scale, lattice parameters, linear absorption coefficients, coordination parameters or oxygen parameters $(X)$, and isothermal parameters. The background level was fitted with a five-order polynomial function and the peak shape with a pseudo-Voigt function. The average crystallite size $(D)$ and the lattice strain of $\mathrm{KSr}_{2}\left(\mathrm{Fe}_{0.25} \mathrm{Nb}_{4.75}\right) \mathrm{O}_{15-\delta}$ of the nanostructured powder were estimated from X-ray diffraction line broadening. The crystallite size was estimated by Scherrer's equation using the Jade 8 Plus software [9]:

$$
D=\frac{k \cdot \lambda}{\beta \cdot \cos \theta}
$$

where $\beta$ is the broadening of the diffraction line measured at half of the maximum intensity, $\lambda$ is the wavelength $(\mathrm{Cu}-\mathrm{K} \alpha), \theta$ is the Bragg angle for a given diffraction, and $\mathrm{k}$ is a constant, which is in general equal to 0.9 for powders. The crystallite size of the precursor powder of $\mathrm{KSr}_{2}\left(\mathrm{Fe}_{0.25} \mathrm{Nb}_{4.75}\right) \mathrm{O}_{15-\delta}$ calcined at $1150^{\circ} \mathrm{C}$ for $12 \mathrm{~h}$ was equal to $25 \mathrm{~nm}$. The instrumental broadening effect was eliminated by subtracting the full width at half-maximum $\left(\beta_{o}\right)$ of a standard sample $\left(\mathrm{SiO}_{2}\right)$ from $\beta$ of the respective Bragg peaks.

\section{Results and Discussion}

The $\mathrm{KSr}_{2}\left(\mathrm{Fe}_{0.25} \mathrm{Nb}_{4.75}\right) \mathrm{O}_{15-\delta}$ powder exhibits only diffraction lines set ascribed to the host structure $\left(\mathrm{KSr}_{2} \mathrm{Nb}_{5} \mathrm{O}_{15}\right)$, a tetragonal tungsten bronze type structure with tetragonal symmetry identified from the JCPDS card number 34-0123. The structural parameters set of the $\mathrm{KSr}_{2}\left(\mathrm{Fe}_{0.25} \mathrm{Nb}_{4.75}\right) \mathrm{O}_{15-\delta}$ solid solution were derived by the Rietveld method using the FullProf program [8]. The X-ray diffraction pattern obtained was indexed on the basis of a tetragonal unit cell. The refinements were performed taking in account the space groups P4bm (No 100), compatible with the rule existence $\left[\left(\begin{array}{llll}0 & k & l\end{array}\right) k=2 n\right]$. The best theoretical adjust for the $\mathrm{KSr}_{2}\left(\mathrm{Fe}_{0.25} \mathrm{Nb}_{4.75}\right) \mathrm{O}_{15-\delta}$ phase was obtained supposing each pentagonal site $(4 c(\mathrm{x}, \mathrm{x}+1 / 2, \mathrm{z}))$ occupied by an equal amount of $\mathrm{K}^{+}$and $\mathrm{Sr}^{2+}$ ions, each tetragonal site $(2 \mathrm{a}(0,0, \mathrm{z}))$ occupied by a $\mathrm{Sr}^{2+}$ ions and for each octahedral site (8d) partially occupied by $\mathrm{Fe}^{3+}$ ions. The trigonal site was considered vacant. The atomic parameters obtained from refinement of $\mathrm{KSr}_{2}\left(\mathrm{Fe}_{0.25} \mathrm{Nb}_{4.75}\right) \mathrm{O}_{15-\delta}$ structure are listed in Table 1. 
Table 1. Atomic coordinates, isotropic atomic displacement parameters $B(\mathrm{eq})(\AA)^{2}$ and relative occupancies $P$ for the $\mathrm{KSr}_{2}\left(\mathrm{Fe}_{0.25} \mathrm{Nb}_{4.75}\right) \mathrm{O}_{15-\delta}$ powder.

\begin{tabular}{ccccccc}
\hline Atoms & $\begin{array}{c}\text { Wyckoff } \\
\text { position }\end{array}$ & $\mathrm{X}$ & $\mathrm{Y}$ & $\mathrm{Z}$ & $\begin{array}{c}B(\mathrm{eq}) \\
(\AA)^{2}\end{array}$ & $\mathrm{P}$ \\
\hline $\mathrm{Sr}(1)$ & $2 \mathrm{a}$ & 0.00000 & 0.00000 & -0.04065 & 1.720 & 0.27 \\
$\mathrm{~K}(2)$ & $4 \mathrm{c}$ & 0.17059 & 0.67059 & -0.02000 & 4.793 & 0.3 \\
$\mathrm{Sr}(2)$ & $4 \mathrm{c}$ & 0.17059 & 0.67059 & -0.02000 & 4.793 & 0.3 \\
$\mathrm{Fe}(1)$ & $2 \mathrm{~b}$ & 0.00000 & 0.50000 & 0.50000 & 3.808 & 0.55 \\
$\mathrm{Nb}(1)$ & $8 \mathrm{~d}$ & 0.07694 & 0.21199 & 0.47793 & 2.942 & 0.3 \\
$\mathrm{Nb}(2)$ & $8 \mathrm{~d}$ & 0.07694 & 0.21199 & 0.47793 & 2.942 & 0.9 \\
$\mathrm{O}(1)$ & $8 \mathrm{~d}$ & 0.13876 & 0.06876 & 0.42562 & 0.998 & 1 \\
$\mathrm{O}(2)$ & $8 \mathrm{~d}$ & 0.33594 & 0.00237 & 0.42145 & 1.818 & 1 \\
$\mathrm{O}(3)$ & $8 \mathrm{~d}$ & 0.08084 & 0.20497 & 0.01667 & 1.818 & 1 \\
$\mathrm{O}(4)$ & $4 \mathrm{c}$ & 0.28536 & 0.78536 & 0.52903 & 1.818 & 0.5 \\
$\mathrm{O}(5)$ & $2 \mathrm{~b}$ & 0.00000 & 0.50000 & -0.06220 & 1.818 & 0.5 \\
\hline
\end{tabular}

Fig. 2 shows the Rietveld graphic for the $\mathrm{KSr}_{2}\left(\mathrm{Fe}_{0.25} \mathrm{Nb}_{4.75}\right) \mathrm{O}_{15-\delta}$ powder with the observed and calculated $\mathrm{X}$-ray diffraction as well as their difference. Lattice parameters derived for the $\mathrm{KSr}_{2}\left(\mathrm{Fe}_{0.25} \mathrm{Nb}_{4.75}\right) \mathrm{O}_{15-\delta}$ are equals to: $a=b=12.4631(2) \AA, c=3.9380(3) \AA$, the volume $\mathrm{V}=$ $611.95(2) \AA^{3}$ and tetragonality ratio $\mathrm{c} / \mathrm{a}=0.315$. These parameters are close to one of the $\mathrm{KSr}_{2} \mathrm{Nb}_{5} \mathrm{O}_{15}$ host structure, which exhibits tetragonality ratio equal to 0.316 [2]. The slight difference of values of lattice parameters between solid solution and host structure might be due the actuation of three major factors. The first one can be associated to the substitution of a part of $\mathrm{Nb}^{5+}$ ions $\left(r_{N b}^{+5}=69 \mathrm{pm}\right)$ by $\mathrm{Fe}^{3+}$ ions $\left(r_{F e}^{+3}=67 \mathrm{pm}\right)$ in the crystalline lattice, which one presents a lower ionic radii. The second one can be related to the smaller average length of the $\mathrm{Fe}-\mathrm{O}$ bond (1.99 $\AA$ ), which is lower than $\mathrm{Nb}-\mathrm{O}$ bonds $(2.01 \AA)$ [4]. The third can be assigned to the non-isovalent niobium substitution, which leads to further structural distortion to accommodate an apparent negative charge excess.

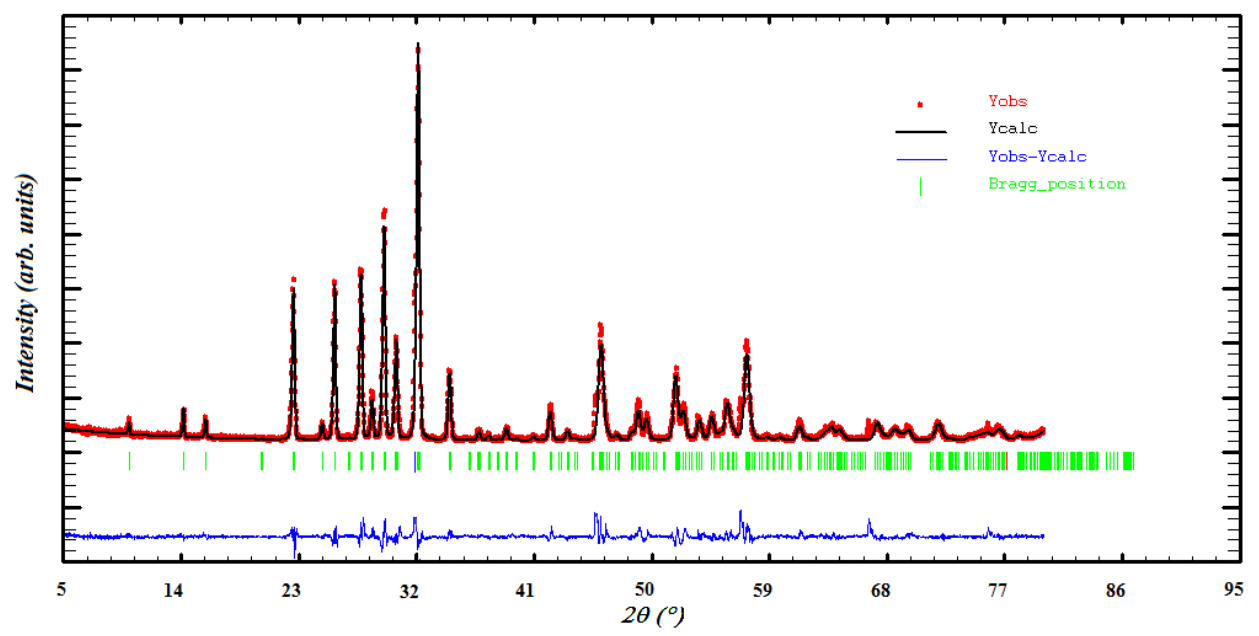

Fig. 2. Rietveld plot for $\mathrm{KSr}_{2}\left(\mathrm{Fe}_{0.25} \mathrm{Nb}_{4.75}\right) \mathrm{O}_{15-\delta}$ powder.

Fig. 3(a) shows the graphic representation of the unit cell obtained for the $\mathrm{KSr}_{2}\left(\mathrm{Fe}_{0.25} \mathrm{Nb}_{4.75}\right) \mathrm{O}_{15-\delta}$ powder along the $a b$ plane from the data listed in Table 1. Niobium and iron atoms are coordinated by oxygen atoms in a 1:6 ratio; four oxygen atoms are located, a priori, in the same plane as the niobium and iron atoms, and another two are located above and below the plane, respectively. In specific, iron cations occupy $\mathrm{Nb}(1)$ positions. Such occupation leads to a distortion of $\left[\mathrm{NbO}_{6}\right]$ polyhedra, which appears to be necessary for the complete structural 
accommodation of the iron [4]. In this sense, both rotation and tilting phenomena of octahedra should occur to further octahedral accommodation. The $\mathrm{Nb}^{5+}$ cations can be differentiated as $\mathrm{Nb}(1)$ and $\mathrm{Nb}(2)$ because they occupy two non-equivalent octahedral sites referred to as $2 b$ and $8 d$, respectively (see Table 1). Both $\left[\mathrm{FeO}_{6}\right]$ and $\left[\mathrm{NbO}_{6}\right]$ polyhedra are represented in Fig. 3 (b) and 3(c), respectively.

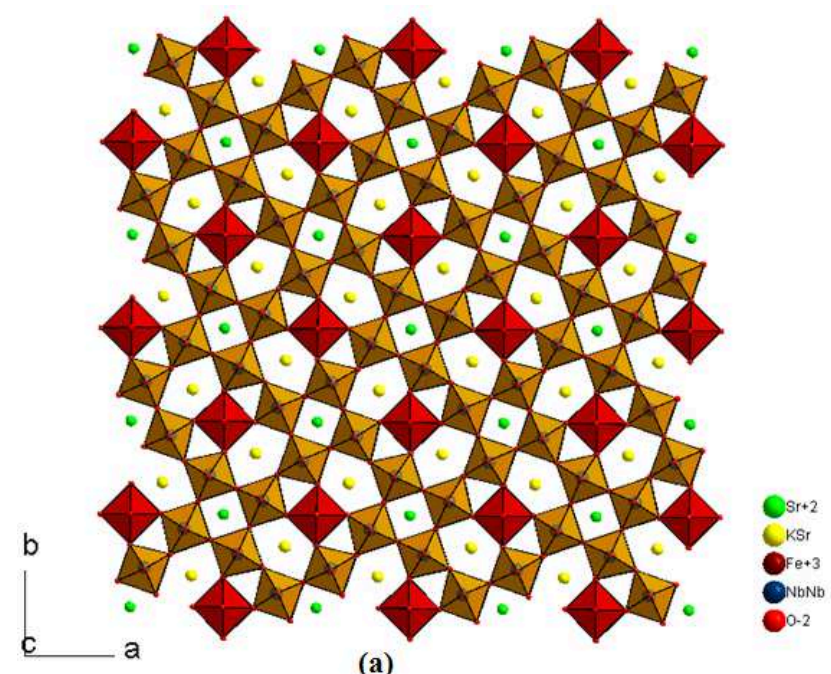

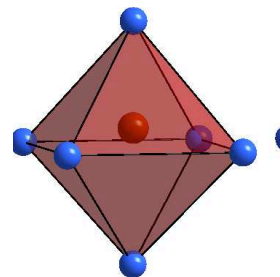

(b)

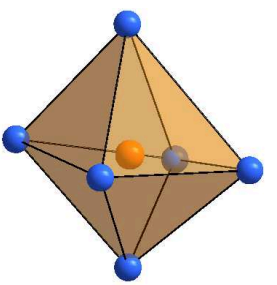

(c)

Fig. 3. (a) Graph of the unit cell obtained for the $\mathrm{KSr}_{2}\left(\mathrm{Fe}_{0.25} \mathrm{Nb}_{4.75}\right) \mathrm{O}_{15-\delta}$ powder, (b) $\left[\mathrm{FeO}_{6}\right]$ and (c) $\left[\mathrm{NbO}_{6}\right]$ octahedral sites.

The $\left[\mathrm{FeO}_{6}\right]$ octahedron shows a lower degree of distortion than the $\left[\mathrm{NbO}_{6}\right]$ octahedron. Some degree of rotation of the $\left[\mathrm{NbO}_{6}\right]$ octahedron along the $c$ axis is apparent. Such distortions are characteristics $\left[\mathrm{NbO}_{6}\right]$ octahedral [10]. The analysis of the $\mathrm{Nb}-\mathrm{O}$ bond lengths of the central plane of the octahedron shows that the $\mathrm{Nb}-\mathrm{O}(2), \mathrm{Nb}-\mathrm{O}(3), \mathrm{Nb}-\mathrm{O}(4)$, and $\mathrm{Nb}-\mathrm{O}(5)$ bonds exhibit distinct lengths. Table 2 shows the lengths of the $\mathrm{Nb}-\mathrm{O}$ and $\mathrm{Fe}-\mathrm{O}$ bonds in both $\left[\mathrm{NbO}_{6}\right]$ and [FeO $\mathrm{Fe}_{6}$ octahedra in Fe-doped $\mathrm{KSr}_{2} \mathrm{Nb}_{5} \mathrm{O}_{15}$. The distinct $\mathrm{Nb}-\mathrm{O}$ bond lengths at the central plane of the octahedron is consistent with the $\left[\mathrm{NbO}_{6}\right]$ rotation. The set of distinct $\mathrm{Nb}-\mathrm{O}$ bond lengths also suggests a tilting of the octahedron. In the $\left[\mathrm{FeO}_{6}\right]$ octahedron, the $\mathrm{Fe}-\mathrm{O}$ bond lengths in the central plane are equal, which means that the octahedron does not undergo rotation, but rather undergoes an elongation. In fact, the $\mathrm{Fe}$ cation exhibits an off-center character. Furthermore, both $\left[\mathrm{FeO}_{6}\right]$ and $\left[\mathrm{NbO}_{6}\right]$ octahedra show an increase of the bond length related to oxygen $\mathrm{O}(1)$ on the apical axis (Fig. 3(b) and (c)). The bond lengths between niobium and the apical oxygens $(\mathrm{O}(1)$ and $\mathrm{O}(6))$ of the $\left[\mathrm{NbO}_{6}\right]$ octahedron are different; this difference is associated with the magnitude of the offcenter displacement of niobium, which is correlated with spontaneous ferroelectric polarization phenomenon.

Table 2. Interatomic distances of $\mathrm{Nb}-\mathrm{O}$ and $\mathrm{Fe}-\mathrm{O}$ bonds in the octahedral sites of $\mathrm{KSr}_{2}\left(\mathrm{Fe}_{0.25} \mathrm{Nb}_{4.75}\right) \mathrm{O}_{15-\delta}$.

\begin{tabular}{|c|c|c|c|c|c|c|}
\hline \multicolumn{7}{|c|}{ [NbO 6 ] Octahedron - Atom: $\mathrm{Nb}(2)$ - Wyckoff position: $8 d^{*}$} \\
\hline Bonds & $\mathrm{Nb}-\mathrm{O}(1)$ & $\mathrm{Nb}^{\xi}-\mathrm{O}(2)$ & $\mathrm{Nb}^{\xi}-\mathrm{O}(3)$ & $\mathrm{Nb}^{\xi}-\mathrm{O}(4)$ & $\mathrm{Nb}^{\xi}-\mathrm{O}(5)$ & $\mathrm{Nb}-\mathrm{O}(6)$ \\
\hline $\begin{array}{c}\text { Interatomic } \\
\text { Distances }(\AA)\end{array}$ & 2.1194 & 2.1032 & 1.8877 & 1.9558 & 1.9558 & 1.8136 \\
\hline \multicolumn{7}{|c|}{ [FeO $\left.{ }_{6}\right]$ Octahedron - Atom: $\mathrm{Fe}(1)-$ Wyckoff position: $2 b^{*}$} \\
\hline Bonds & $\mathrm{Fe}-\mathrm{O}(1)$ & $\mathrm{Fe}^{\xi}-\mathrm{O}(2)$ & $\mathrm{Fe}^{\xi}-\mathrm{O}(3)$ & $\mathrm{Fe}^{\xi}-\mathrm{O}(4)$ & $\mathrm{Fe}^{\xi}-\mathrm{O}(5)$ & $\mathrm{Fe}-\mathrm{O}(6)$ \\
\hline $\begin{array}{c}\text { Interatomic } \\
\text { Distances }(\AA)\end{array}$ & 1.7082 & 2.0696 & 2.0696 & 2.0696 & 2.0696 & 2.0096 \\
\hline
\end{tabular}


In niobates, the spontaneous polarization ascribed to the intrinsic ferroelectricity is a function of parameter $\Delta z$ ( $\mathrm{Nb}$ off-center), which gives the magnitude of the $\mathrm{Nb}$ displacement from the central position of the $\left[\mathrm{NbO}_{6}\right]$ octahedron [4]. The value of $z$ (coordinate of $\mathrm{Nb}(2)$ in $8 d$ sites) is different from $z=1 / 2$. The difference between both apical lengths $[(\mathrm{Nb}-\mathrm{O} 6)$ and $(\mathrm{Nb}-\mathrm{O} 1)]$ is twice the niobium off-center displacement of $\Delta z$ (see Fig. 3 (c)). The spontaneous polarization, $\mathrm{P}_{\mathrm{S}}$, associated with $\left[\mathrm{NbO}_{6}\right]$ depends on the magnitude of niobium off-center displacement $\Delta z$. The magnitude of the displacement of $\left[\mathrm{NbO}_{6}\right]$ is $0.1529 \AA$. The magnitude of the $\mathrm{P}_{\mathrm{S}}$ parameter can be roughly estimated by the classical relation [11]:

$$
\mathrm{P}_{\mathrm{S}}=(258 \pm 9) \Delta \mathrm{z} \mu \mathrm{C} \mathrm{cm}{ }^{-2}
$$

The spontaneous polarization of the $\mathrm{KSr}_{2}\left(\mathrm{Fe}_{0.25} \mathrm{Nb}_{4.75}\right) \mathrm{O}_{15-\delta}$ powder derived from Eq. (2) was 39.4 $\mu \mathrm{C} . \mathrm{cm}^{-2}$, at room temperature. The value derived is about sixteen times higher than that obtained for the spontaneous polarization based on the $\left[\mathrm{NbO}_{6}\right]$ octahedra distortion in the $\mathrm{KSr}_{2} \mathrm{Nb}_{5} \mathrm{O}_{15}$ structure, which has been derived being equal to $2.46 \mu \mathrm{C} \mathrm{cm}^{-2}[12]$.

\section{Conclusion}

Modified Polyol Method is suitable for the preparation of nanostructured and single-phase polycation of $\mathrm{KSr}_{2}\left(\mathrm{Fe}_{0.25} \mathrm{Nb}_{4.75}\right) \mathrm{O}_{15-\delta}$ with highly stable crystalline particles at high temperature, with very small sizes. The non-isovalent substitution of $\mathrm{Nb}$ cations does not change the distribution of $\mathrm{K}$ and $\mathrm{Sr}$ cations in the unit cell; the pentagonal sites are occupied by statistically equal quantities of $\mathrm{K}^{+}$and $\mathrm{Sr}^{2+}$ ions and each tetragonal sites by $\mathrm{Sr}^{2+}$ ions. The $\mathrm{Fe}^{3+}$ ions occupy octahedral sites, which are referred to as $\mathrm{Nb}(1)$ positions. This occupation leads to stabilization of structure via distortions of the $\left[\mathrm{NbO}_{6}\right]$ polyhedra; these distortions induce the stabilization of offcenter characteristic of the $\mathrm{Nb}^{5+}$ cations.

\section{Acknowledgements}

The authors are grateful to the Brazilian research agencies: FAPESP, CNPq, Capes and UNESP/PROPe for financial support.

\section{References}

[1] H.E.A. Belghiti, A. Simon, P. Gravereau, A.Villesuzanne, M. Elaatmani, J. Ravez: Sol. State Sci. Vol. 4 (2002), p. 933.

[2] S. Lanfredi, C.X. Cardoso, M.A.L. Nobre: Mater. Sci. Eng. B Vol. 112 (2004), p.139.

[3] S. Lanfredi, D.H.M. Gênova, I.A.O. Brito, A.R.F. Lima, M.A.L. Nobre: J. Solid State Chem. Vol. 184 (2011), p. 990.

[4] A.R.F. Lima, S. Lanfredi, M.A.L. Nobre: Quim. Nova, Vol. 33 (2010), p.1071.

[5] S. Lanfredi, C. Darie, F.S. Bellucci, C.V. Colin, M.A.L. Nobre: Dalton Trans. Vol 43 (2014), p. 10983.

[6] S. Lanfredi, I.A.O Brito, C.Polini, M.A.L.Nobre: J. Appl. Spectros. Vol.79 (2012), p. 254.

[7] M. P.Pechini, U.S. Patent, No. 3.330.697 (1967).

[8] J.R. Carvajal, An introduction to the Program FullProff 2000, CEA/Saclay, France (2008).

[9] Jade 8 Plus, XRD Pattern Processing and Identification Program, Materials Data, Inc. 19952007.

[10] K.M. Ok, J. Orzechowski, P.S. Halasyamani: Inorg. Chem. Vol. 43 (2004), p. 964.

[11] S.C. Abrahams, S.K. Kurtz, P.B. Jamieson: Phys. Rev. Vol. 172 (1968), p. 551.

[12] S. Alkoy, C. Duran, D.A. Hall: J. Am. Ceram. Soc. Vol. 91 (2008), p. 1597. 


\section{Brazilian Ceramic Conference 58}

10.4028/www.scientific.net/MSF.820

\section{Changing of the Spontaneous Polarization in Niobate Nanoparticles Induced by Non Isovalent Doping} 10.4028/www.scientific.net/MSF.820.367

\section{DOI References}

[1] H.E.A. Belghiti, A. Simon, P. Gravereau, A. Villesuzanne, M. Elaatmani, J. Ravez: Sol. State Sci. Vol. 4 (2002), p.933.

10.1016/S1293-2558(02)01343-2

[2] S. Lanfredi, C.X. Cardoso, M.A.L. Nobre: Mater. Sci. Eng. B Vol. 112 (2004), p.139.

10.1016/j.mseb.2004.05.021

[3] S. Lanfredi, D.H.M. Gênova, I.A.O. Brito, A.R.F. Lima, M.A.L. Nobre: J. Solid State Chem. Vol. 184

(2011), p.990.

10.1016/j.jssc.2011.03.001

[4] A.R.F. Lima, S. Lanfredi, M.A.L. Nobre: Quim. Nova, Vol. 33 (2010), p.1071.

10.1590/S0100-40422010000500012

[6] S. Lanfredi, I.A. O Brito, C. Polini, M.A.L. Nobre: J. Appl. Spectros. Vol. 79 (2012), p.254.

10.1007/s10812-012-9592-4

[10] K.M. Ok, J. Orzechowski, P.S. Halasyamani: Inorg. Chem. Vol. 43 (2004), p.964.

$10.1021 / \mathrm{ic} 0350335$

[11] S.C. Abrahams, S.K. Kurtz, P.B. Jamieson: Phys. Rev. Vol. 172 (1968), p.551.

10.1103/PhysRev.172.551

[12] S. Alkoy, C. Duran, D.A. Hall: J. Am. Ceram. Soc. Vol. 91 (2008), p.1597.

10.1111/j.1551-2916.2008.02342.x 
Reproduced with permission of the copyright owner. Further reproduction prohibited without permission. 